\title{
The Moon's Shadow in Relation to the Earth on June 29.
}

By Dr. E. H. RAYNer. THE shadow of the moon, considered as a miles long, intersects the earth at Cardigan Bay at $5^{\text {h }} 23^{\mathrm{m}}$ G.M.T. At this moment the imaginary point of the shadow is about 1500 miles within the earth. The average diameter of the shadow as it crosses England is about 15 miles where it intersects the earth, being the value of the minor axis of the elliptical area of the earth's surface within which the eclipse is total at any moment. The altitude of the sun being about $11^{\circ}$, the major axis of the ellipse is four to five times as long as the minor axis. The azimuth of the sun is some $20^{\circ}$ to the south of the direction of the shadow track ; and this, combined with the elliptical form, causes the width of the track of totality to be about twice the diameter of the shadow cone.

The accompanying illustration (Fig. 1) shows a model of the conical shadow at $5^{\mathrm{h}} 23^{\mathrm{m}}$. The scale of the model is 10 miles to the inch, which is that of the special Ordnance Survey Map. It will be seen that the centre line of the shadow crosses the east coast of England over south Yorkshire at a

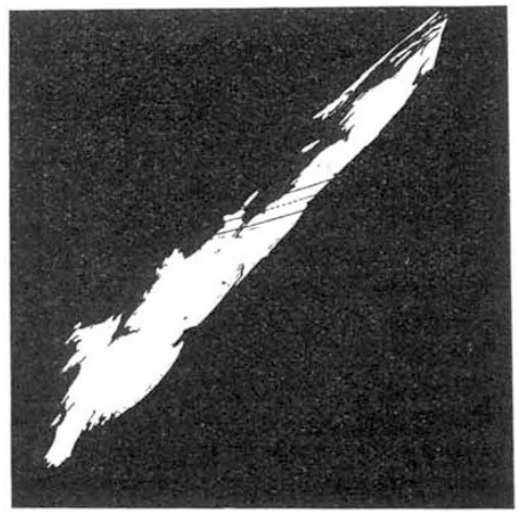

FIG. 2.-Position and orientation of England during the eclipse.

height of about 45 miles. An important height from the point of view of radio transmission is about 100 kilometres, or 60 miles. The intersection of the centre of the shadow with this level has therefore passed over England towards the east before the intersection at the earth's surface has arrived at Wales from the south-west. The plan position of the intersection at a height of 60 miles has been specially computed by Dr. L. J. Comrie

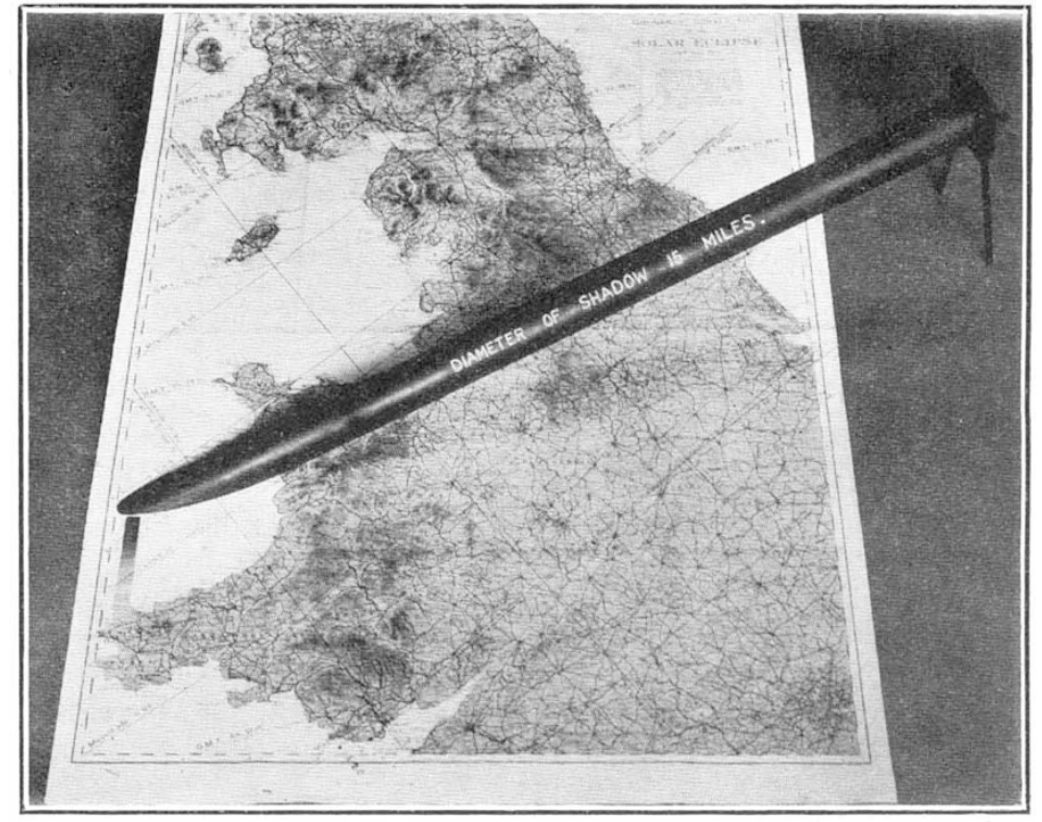

FIG. 1.-Three-dimensional model of shadow of the moon near the earth's surface.

on behalf of the Radio Research Board, to whom
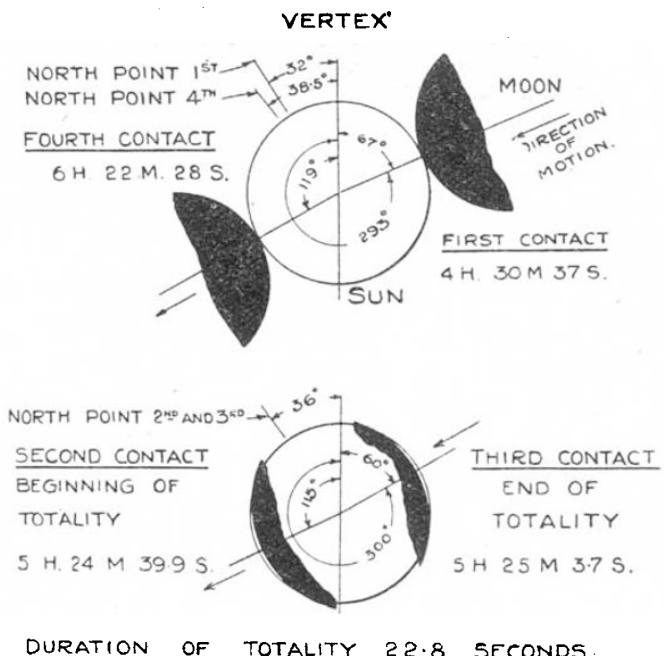

TIMES OF CONTACT AND POSITION ANGLES. FOR LAT. $54^{\circ} 24.6^{\prime} \mathrm{N}$. $1^{\circ} 45.5 \mathrm{~W}$. BEING THE POSITION. OF THE S.W. CORNER OF RICHMOND RACE COURSE

FIG. 3.-Circumstances of the eclipse for Richmond, Yorkshire,

I am indebted for much of the information of a numerical character. 
Over England the plan position of the intersection at 60 miles high runs nearly parallel to the 0.98 totality line to the south of the central track. It is for most of the distance between the Bristol Channel and the North Sea, within 2 to 5 miles of this line and to the south of it. The location at $5^{\mathrm{h}} 20^{\mathrm{m}}$ is shown in the lower margin of the illustration, and that at $5^{\mathrm{h}} 22^{\mathrm{m}}$ is near the east coast. It is interesting to note that according to the data used in the computation, the centre of the shadow has not reached the earth's surface at $5^{\mathrm{h}} 20^{\mathrm{m}}$, its nominal time of contact being $5^{\mathrm{h}} 20 \cdot 1^{\mathrm{m}}$.

The season and the early time of day at which the eclipse takes place, being before 6 A.M. by solar time for first, second, and third contacts, causes the lines indicating simultaneous maximum phase on the map to be displaced more than $90^{\circ}$ from the lines of longitude to which they approximate later in the day where the eclipse takes place at local noon. The map (Fig. 2) shows the shape of England as viewed in the direction of the shadow axis, the plane containing the earth's axis being imagined to indicate the vertical.

Arrangements have been made for the party organised by the Physical Society of London to have the use of accommodation at the Race Course at Richmond. The times of the contacts and position angles are shown in Fig. 3. The computation has been made taking into account the corrections given by Dr. Comrie, as a result of the information recently provided by the Astronomer Royal. The difference between the position angles of second and third contacts, $185^{\circ}$, being larger than $180^{\circ}$, shows that the point is a few hundred yards to the north of the centre line.

\section{Astronomical Programmes of Eclipse Work.}

\section{By F. J. M. Stratton.}

$\mathrm{A}^{\mathrm{T}}$ LTHOUGH the Joint Permanent Eclipse Committee has organised no special expedition to observe the eclipse of June 29 , it has arranged that all instruments in its charge should be employed at the eclipse and has acted as an intermediary in securing instruments and local facilities for various expeditions. Ready co-operation has been invariably met with locally.

The first eclipse camp on the track of which the programme details are available is at Llysfaen Head, near Colwyn Bay. Here Dr. R. J. Clark, of the University of Edinburgh, Prof. H. Dingle, of the Imperial College of Science and Technology, South Kensington, and a group of research students from the University of Cambridge, will be stationed. A 16-inch cœlostat will be used to feed two spectrographs-a slit spectrograph working with a very dense flint Parsons prism, and an objective gratingspectrograph using a parabolic grating lent by Mr. Merfield of Melbourne, especially ruled to be strong in the infra-red of the first order and the ultra-violet of the second order. Abney plates will be used, and it is hoped to extend the spectrum of the chromosphere, and if possible of the corona, well beyond $\lambda 10,000$. Wireless experiments on the strength of signals will also be carried out. Prof. Nolan from Dublin will also be at Colwyn Bay studying atmospheric electricity during the eclipse, and possibly President Morehouse from Des Moines University, Iowa, may be there with a spectroscopic programme.

Where the eclipse track strikes land again at Southport, the Oxford expedition under Prof. H.H. Turner and Dr. H. Knox-Shaw will be stationed. Their programme consists of direct photography of the corona together with photographs in polarised light. At Stonyhurst, Father O'Connor will also be taking direct photographs of the corona and flash spectra, working 'so far as possible into the infra-red. It is understood that Prof. da Costa Lobo, Director of the Coimbra Observatory, Portugal, will be at Stonyhurst with a cinema camera and spectroscopic apparatus.

The expedition from the Royal Observatory, Greenwich, will be in the grounds of Giggleswick School, near Settle. Its programme consists of direct photographs of the corona with a 6-inch lens of $45 \mathrm{ft}$. focal length, the spectrum of the chromosphere in the extreme red and a comparison of the intensities and heights of $\mathrm{H}$ and $\mathrm{K}$ and of the $\mathrm{Ca}^{+}$triplet ${ }^{2} D-{ }^{2} F$ at $\lambda \lambda 8498,8542,8662$.

Mr. Evershed will be at Tunstall, about five miles from the central line, working. with a large prismatic camera with two 6 -inch prisms of $45^{\circ}$ angle and a lens of $21 \mathrm{ft}$. focus. He will be studying the cusp spectrum before and after totality and the flash spectrum, and will be largely concerned with the height of the various gases. The Norman Lockyer Observatory expedition will be between Gilling and Richmond with a programme of direct photographs of the corona and small-scale spectra. Other observers who are expected to carry out observations in the belt of totality in Great Britain include Mr. Albert Taylor at Llanbedrog, Prof. E. A. Owen at Bangor., Mr. Harold Thomson and Mr. F. Sargent, of the Observatory of Durham, at Catterick, Dr. F. W. Aston and Mr. Wilfrid Hall also in Yorkshire. Prof. A. Fowler at the Imperial College of Science and Technology, London, and Prof. R. A. Sampson at Edinburgh, are proposing to study the cusp spectrum with high dispersion spectrographs during a considerable interval on either side of the time of maximum eclipse.

The other British expedition is that of the Solar Physics Observatory, University of Cambridge, which proceeds under Prof. H. F. Newall to Aal, in the Hallingdal in Norway. In addition to direct 